\begin{tabular}{|c|c|}
\hline $\begin{array}{l}\text { Chemistry of } \\
\text { Metals and Allovs }\end{array}$ & 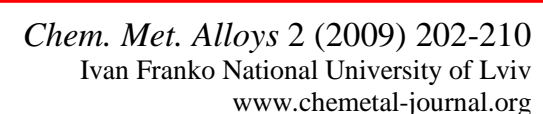 \\
\hline
\end{tabular}

\title{
Corrosion protection of mild steel electrode by electrochemical polymerization of acrylamide
}

\author{
H. SHOKRY $Y^{1,2 *}$ \\ ${ }^{1}$ Chemistry Department, Faculty of Science, Kafer El-Sheikh University, Kafer El-Sheikh, Egypt \\ ${ }^{2}$ Chemistry Department, Faculty of Applied Science (Girls), Umm-Al Qura University, Makkah, KSA \\ * Corresponding author. E-mail:dr_H_shokry@hotmail.com
}

Received December 15, 2009; accepted December 23, 2009; available on-line April 27, 2010

Polyacrylamide (PAA) film was electrosynthesized on mild steel by cyclic voltammetry using a Ce(IV) salt oxalic acid initiator system. Polymerization was initiated by a free radical that is formed by fast reaction of oxalic acid and $\mathrm{Ce}(\mathrm{IV})$. The electrolysis of the solution results in regeneration of $\mathrm{Ce}(\mathrm{IV})$, which can oxidize the oxalic acid and produce radicals. The effect of temperature on the yield of the electroinitiated polymerization was studied. The potential sweep rate was changed to achieve polymer films with different levels of thickness. The capacity of the PAA film to protect mild steel from corrosion in an $1 \mathrm{M} \mathrm{NaCl}$ aqueous solution was investigated by potentiodynamic polarization curves and electrochemical impedance spectroscopy (EIS). The structure of the PAA film on mild steel was investigated by physicochemical methods such as elemental analysis of $\mathrm{C}, \mathrm{H}$ and $\mathrm{N}$ by a FTIR spectrometer. The results of the studies reveal that the corrosion resistance of PAA-coated mild steel is significantly higher and the corrosion rate considerably lower than for uncoated steel. PAA films formed with lower sweep rates exhibited a larger positive shift of the corrosion potential and greater charge transfer resistance, reflecting as higher inhibitors for corrosion of mild steel.

\section{Polyacrylamide / Electrochemical / Potentiodynamic / Impedance / Protection / Corrosion}

\section{Introduction}

Corrosion is an electrochemical reaction based on universal laws of Nature. All metallic structures corrode. Steel, for example, is a man made substance produced from iron oxide. The energy added in the refining process is unstable and, in a suitable environment, the steel will release this energy and return to its natural state of iron ore.

Polymer adsorption onto solid surfaces is important for a wide range of applications, and is relevant to many issues in biology and medicine. Adsorbed polymer layers are widely used in the stabilization of colloidal suspensions and are essential for the forming of paints, coatings, printing inks, drilling needs, and for the processing of ceramics $[1,2]$. They also play a crucial role in protecting against corrosion [3-5], as well as in many biological applications such as boundary lubricants [2].

Isolation of metals from the corrosive environment is probably the most general mechanism of protecting against corrosion offered by polymer coating. Proper isolation by polymer coating requires that the polymeric material provides the correct barrier properties and remains adherent in the presence of water and corrosive products such as $\mathrm{Fe}_{2} \mathrm{O}_{3}$.
Polymer films, based on aniline-, phenol-, normal vinyl- and heterocyclic vinyl-type monomers, have been synthesized on mild steel by various kinds of electropolymerization (EP) and their corrosion resistance studied. Electrooxidation polymerization (EOP) produced incomplete, porous and thin films on the steel surface. The most corrosion-preventing film under the experimental conditions was a poly (2-vinylpyridine) film with a corrosion inhibitor efficiency of about 80-90\% [6].

Potentiodynamic polarization curves were obtained for carbon and stainless steel in contact with a $3 \%$ sodium chloride aqueous solution saturated with air, in order to evaluate the capacity of polyaniline in the emeraldine oxidation state to protect the surface against corrosion [7].

As shown by ellipsometry, the chemisorption of PAA on a bare silver surface is more pronounced than on a $\mathrm{Ti} / \mathrm{TiO}_{2}$ interface. The presence of PAA in a boric borate buffer, $\mathrm{pH} 8.4$, mostly inhibits the process in the active region of passivation of iron [8]. These results show that PAA adsorbs mainly on bare active metal surfaces.

Electropolymerized (EP) polymers have been studied using vinyl-type polymers such as polyacrylonitrile, polyacrylic acid (polypropenoic 
acid), polyacrylamide, polyacrolein, and so on [9-14], which were synthesized by electroreduction (cathodic reduction) polymerization (ERP). Aryl-type polymers such as polyphenylene oxide, polyaniline, polythiophene, and their derivatives [15-18], which were synthesized by electrooxidation (anodic oxidation) polymerization (EOP), ERP, and so on, have also been studied. However, for EP films coated on mild steel the relationship between the method of electropolymerization, the structure of the polymerized film, and the evolution of the corrosion resistance has not yet been studied systematically.

The objective of the present study was (a) to synthesize uniform, compact and strongly adherent PAA coatings on mild steel substrates; and (b) to study the corrosion behavior of a PAA coating deposited on mild steel in corrosive environment by the potentiodynamic polarization technique and electrochemical impedance spectroscopy (EIS).

\section{Experimental}

\section{Materials}

$\mathrm{Ce}\left(\mathrm{SO}_{4}\right)_{2} \cdot 4 \mathrm{H}_{2} \mathrm{O}$, oxalic acid (OA), sulfuric acid, and acrylamide (AA) (Merck) were all reagent-grade chemicals and used without further purification.

\section{Electrochemical polymerization}

EP of AA was studied in an aqueous solution in the presence of $\mathrm{Ce}(\mathrm{IV})$-oxalic acid redox initiator systems at a constant current density of $1 \mathrm{~mA} / \mathrm{cm}^{2}$ in the temperature range $20-70{ }^{\circ} \mathrm{C}$. The cyclic voltammetry method was applied between -0.2 and $1.1 \mathrm{~V}$ (vs. a saturated calomel electrode) at sweep rates of 0.02 , 0.05 and $0.1 \mathrm{~V} / \mathrm{s}$. The current efficiencies, $\eta_{i}$, for the electrodeposition were determined from the following equation [19].

$\eta_{i}=\frac{(2+y)\left(\Delta m F+0.5 \tau_{\text {ind }} I M_{F e}\right)}{Q\left(M_{m}+y M_{A}\right)}$

where $\Delta m$ is the experimental mass difference between the blank sheet and the coated sheet, $I$ is the electrodepositing current, $\tau_{\text {ind }}$ is the induction time during which iron dissolves, $M_{m}$ is the molecular weight of the monomer (AA), $M_{A}$ is the molecular weight of the inserted anion, $M_{\mathrm{Fe}}$ is the atomic weight of iron, $Q$ is the charge for electrodeposition of PAA ( $Q$ corresponds to the positive potential plateau where PAA is formed), and $y$ is the degree of insertion of anions into the polymer film during its electrodeposition. The thickness $\delta$ of the PAA deposit was determined using the following equation:

$\delta=\frac{m_{\tau P A A} \eta_{i}}{A \rho}=\frac{Q\left(M_{m}+y M_{A}\right) \eta_{i}}{(2+y) F A \rho}$

where $m_{\tau P A A}$ corresponds to the theoretical mass of the PAA deposit with $\eta_{i}=100 \%$.

The approximate average molecular weight of the polymer, $M_{v}$, was determined from viscosity measurements in water at $30{ }^{\circ} \mathrm{C}$ by an Ubbelohde viscometer, using the equation given in [20]:

$[\eta]=6.8 \times 10^{-4} \bar{M}_{v}^{0.66} d \mathrm{Lg}^{-1}$

The film formation process was analyzed by physicochemical methods. The formation and growth was checked by gravimetry. The apparent coating thickness was determined in a constant potential electrolysis using a two-electrode cell. Structural analyses were performed on films and coated steel plates were scraped off and examined by physicochemical methods. For the elemental analysis of $\mathrm{C}, \mathrm{H}$ and N, FTIR spectra were obtained on a Perkin-Elmer 1420 spectrophotometer, using a $\mathrm{KBr}$ disk.

\section{Electrochemical measurements}

The potentiodynamic polarization technique was applied in a standard three-electrode cell using a Potentiostat /Galvanostat (Toho Technical Research) and an $\mathrm{x}-\mathrm{y}$ recorder. A mild steel disk was used as a working electrode; the chemical composition (percent) was C $0.04, \mathrm{Si}$ trace, $\mathrm{Mn} \mathrm{0.3,} \mathrm{P} \mathrm{0.02,} \mathrm{S} 0.017$ and Fe balance, and the surface of the steel disk was polished with silicon carbide emery paper up to 1500 grade. The counter electrode was a platinum plate and wire and the reference electrode was a saturated calomel electrode (SCE).

The performance of the protection against corrosion of these coatings was investigated in an aqueous $1 \mathrm{M} \mathrm{NaCl}$ solution, by using the potentiodynamic polarization technique and EIS. For these measurements, a Teflon holder was used to encase the polymer coated mild steel substrates so as to leave an area of $30 \mathrm{~mm}^{2}$ exposed to the solution. The potentiodynamic polarization measurements were performed by sweeping the potential between -0.2 and $1.1 \mathrm{~V}$ from an open circuit potential at the scan rate of $0.001 \mathrm{~V} / \mathrm{s}$. The substrates were allowed to stabilize in the electrolyte for $30 \mathrm{~min}$ prior to the potentiodynamic polarization measurements. The Travel slopes of the anodic $\beta_{a}$ and cathodic $\beta_{c}$ parts of the polarization curve were obtained. The corrosion current density $\left(I_{\text {corr }}\right)$ in $\mathrm{A} / \mathrm{m}^{2}$ was calculated by using the Stern-Geary equation [21] and converted into the corrosion rate $(C R)$ in $\mathrm{mm} /$ year by applying the following equation [22]:

$C R(\mathrm{~mm} / \mathrm{yr})=3.268 \times 10^{3} \frac{I_{\text {corr }}}{\rho} \frac{M W}{z}$

where $M W$ is the molecular weight of mild steel $(\mathrm{g}), \rho$ is the density of mild steel $\left(\mathrm{kg} / \mathrm{m}^{3}\right)$ and $z$ is the number of electrons transferred in the corrosion reaction; $z=2$ in the case of mild steel.

EIS measurements of PAA-coated and uncoated mild steel were carried out at the open circuit potential in an aqueous solution of $1 \mathrm{M} \mathrm{NaCl}$. The frequency was varied from $0.1 \mathrm{~Hz}$ to $20 \mathrm{kHz}$ using an ac excitation potential of $10 \mathrm{mV}$ amplitude of sinusoidal 
voltage signal, applied by using a frequency response analyzer (FRA, NF Electronic Instruments, FRA 5020), a Potentiostat / Galvanostat (Toho Technical Research) and a data processor (personal computer, NEC, PC-9801). All experiments were carried out at $25^{\circ} \mathrm{C}$ as described in previous papers [23,24]. The impedance spectra were analyzed by fitting the experimental results to equivalent circuits using a nonlinear least-squares fitting procedure.

\section{Results and discussion}

PAA films can be produced both by chemical and electrochemical methods. The advantage of the electrochemical synthesis is that it is a direct synthesis of the polymer on the metal surface without any organic additives. This is an advantage when studying the protection mechanism of a pure polymer.

The effect of temperature on the polymerization yield was investigated for the polymerization by both electro and chemical methods, as shown in Table 1. The highest yield for electro polymerization was obtained at $50{ }^{\circ} \mathrm{C}$. This differs from the conventional chemical method, where the free radical regeneration rate was mainly controlled by the temperature.

In the absence of ceric ions and oxalic acid the electro polymerization of AA was not initiated. Consequently, PAA films cannot be produced under these conditions.

A schematic overview of the redox polymerization is presented in Fig. 1. It shows that the polymerization is initiated by a free radical formed by fast reaction of oxalic acid and $\mathrm{Ce}(\mathrm{VI})$. The electrolysis of the solution results in regeneration of $\mathrm{Ce}(\mathrm{VI})$, which can oxidize the oxalic acid and produce radicals.

Table 1 Conversion yield of electrochemical polymerization of PAA at different temperatures.

\begin{tabular}{c|c}
\hline Temperature $\left({ }^{\circ} \mathrm{C}\right)$ & Conversion $(\%)$ \\
\hline 22 & 45 \\
35 & 57 \\
50 & 65 \\
70 & 60 \\
\hline
\end{tabular}

$\left[\mathrm{H}_{2} \mathrm{SO}_{4}\right]=0.5 \mathrm{M},[\mathrm{AA}]=0.5 \mathrm{M},[\mathrm{Ce}(\mathrm{IV})]=5 \times 10^{-4} \mathrm{M}$, $[\mathrm{OA}]=2 \times 10^{-2} \mathrm{M}$.

A FTIR spectrum of the polymer formed on the steel surface is seen in Fig. 2. This spectrum resembles the spectra of PAA reported in earlier works [25-27]. The elemental composition of the PAA was determined (in \%) as C 51.29, H 6.92, N 18.99, and $\mathrm{O} 22.8$.

The average molecular weights of PAA obtained for different acid concentrations are summarized in Table 2. The average molecular weight of the polymer decreased with increasing concentration of sulfuric acid. This was expected because increases in the initiator concentration increase the growing chain population, which in turn enhances the polymerization rate and simultaneously lowers the molecular weight of the polymer.

Preliminary results indicate that the structure and properties of PAA coating formed on mild steel vary with the conditions. The longer the passivation time $(\tau)$, the better the quality of the coating. Electropolymerization of PAA on mild steel is preceded by the coverage of the substrate by a crystalline passive film. The process goes through three distinct stages:

1) dissolution of steel, followed by

2) passivation of steel, and finally

3) deposition of PAA.

The passivation time can be decreased by increasing the applied current [28], as shown in Table 3. Fig. 3 displays potential vs. time curves for electrodeposition of PAA onto mild steel at a constant current density of $1 \mathrm{~mA} / \mathrm{cm}^{2}$. The induction period, $\tau_{\text {ind }}$, is attributed to the active dissolution of iron at negative potentials. After $10 \mathrm{~min}$ the potential is shifted in the positive direction as the result of precipitation of $\mathrm{Fe}(\mathrm{II})$ oxalate, and PAA film is electrodeposited at the positive potential plateau. The pronounced potential peak preceding the plateau was attributed to the formation of an $\mathrm{Fe}$ (II) oxalate interlayer [19] at the beginning of the electrodeposition of the PAA film.

Table 2 Average molecular weight and conversion yield for PAA film.

\begin{tabular}{l|c|c}
\hline$\left[\mathrm{H}_{2} \mathrm{SO}_{4}\right](\mathrm{M})$ & Conversion (\%) & $\overline{M_{v}}$ \\
\hline 0.05 & 25 & 34,000 \\
0.5 & 89 & 13,000 \\
\hline$[\mathrm{AA}]=0.5 \mathrm{M}$, & {$[\mathrm{Ce}(\mathrm{IV})]=5 \times 10^{-4} \mathrm{M} \quad$ and } \\
{$[\mathrm{OA}]=2 \times 10^{-2} \mathrm{M}, T=25^{\circ} \mathrm{C}, E=1.2 \mathrm{~V}, I=40 \mathrm{~mA}$,} \\
$\tau=1 \mathrm{~h}$.
\end{tabular}

Table 3 Dependence of the passivation time and charge on the applied current.

\begin{tabular}{c|c|c}
\hline $\begin{array}{c}\text { Current density } \\
\left(\mathrm{mA} / \mathrm{cm}^{2}\right)\end{array}$ & $\begin{array}{c}\text { Passivation time } \\
(\mathrm{s})\end{array}$ & $\begin{array}{c}\text { Passivation charge } \\
\left(\mathrm{mC} / \mathrm{cm}^{2}\right)\end{array}$ \\
\hline 1.0 & 420 & 300 \\
3.0 & 60 & 200 \\
7.5 & 20 & 210 \\
10 & 15 & 150 \\
\hline
\end{tabular}

The behavior described above indicates that the iron dissolution of pretreated steel is very low. As a result the PAA film is homogeneous and adherent to the steel surface. The thickness of the coating was calculated under the assumption that the density of the film is $\rho=1.5 \mathrm{~g} / \mathrm{cm}^{3}$ and using equation 2 . The data shown in the Table 4 was calculated for $y=0.2$. 
$\underline{\text { Redox polymerization }}$

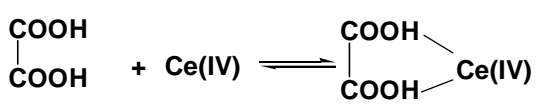

Initiation
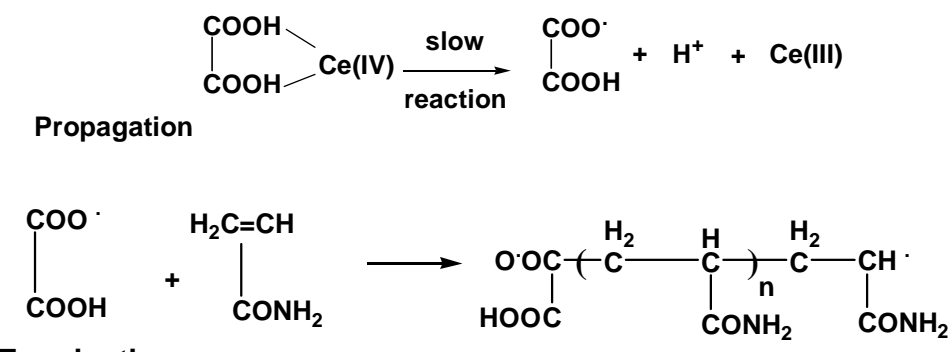

Termination

Electrochemical polymerization
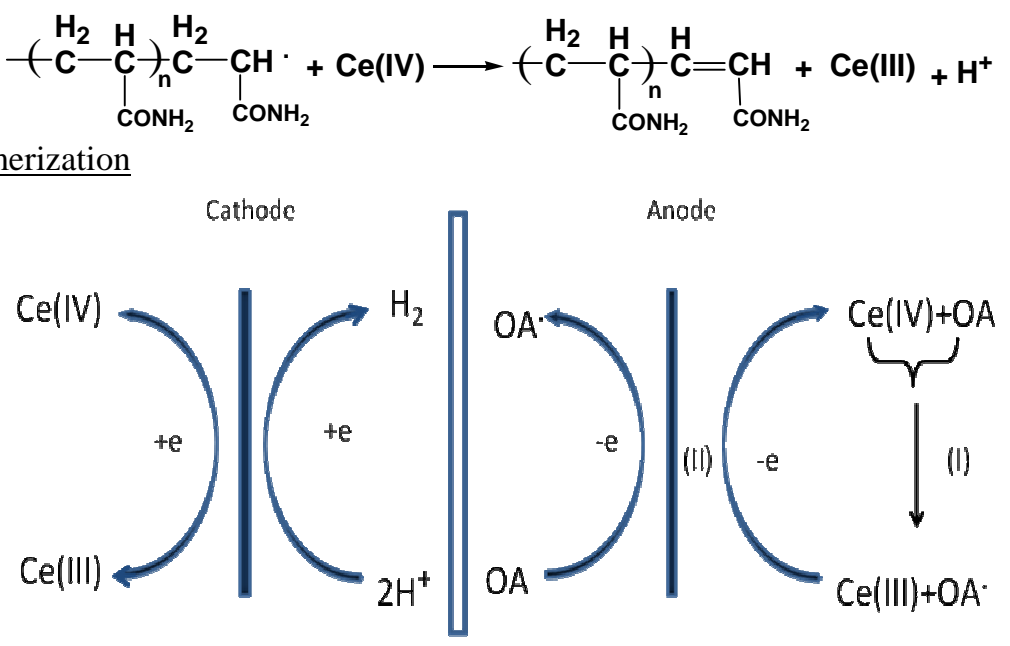

1) Redox initiation

II) Electrogeneration

I)+II) Electroinduced redox initiation

Fig. 1 Schematic representation of the polymerization of PAA.

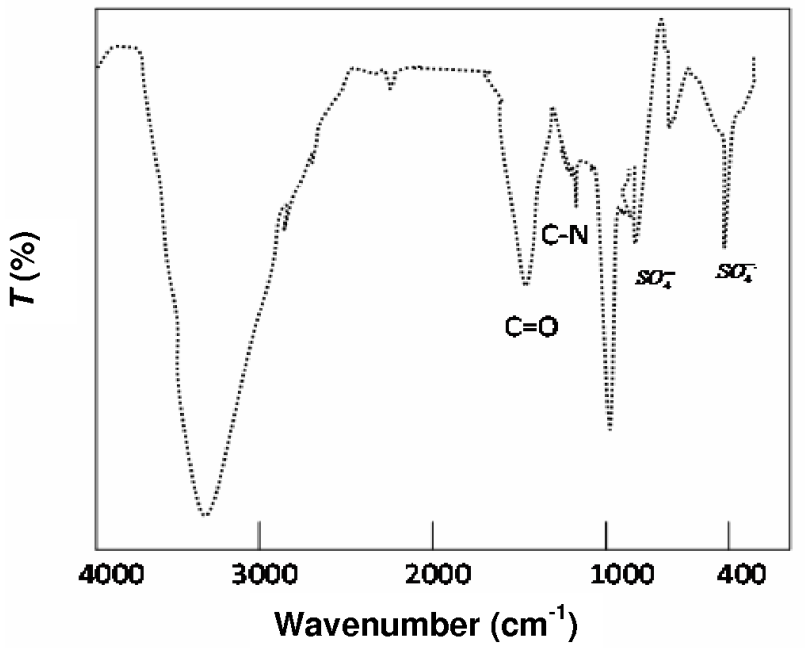

Fig. 2 FTIR spectra of PAA obtained on the surface of mild steel; $\left[\mathrm{H}_{2} \mathrm{SO}_{4}\right]=0.1 \mathrm{M},[\mathrm{AA}]=0.5 \mathrm{M}$, $[\mathrm{Ce}(\mathrm{IV})]=5 \times 10^{-4} \mathrm{M},[\mathrm{OA}]=2 \times 10^{-2} \mathrm{M}, E=1.2 \mathrm{~V}, I=40 \mathrm{~mA}$, deposition time $1 \mathrm{~h}$. 


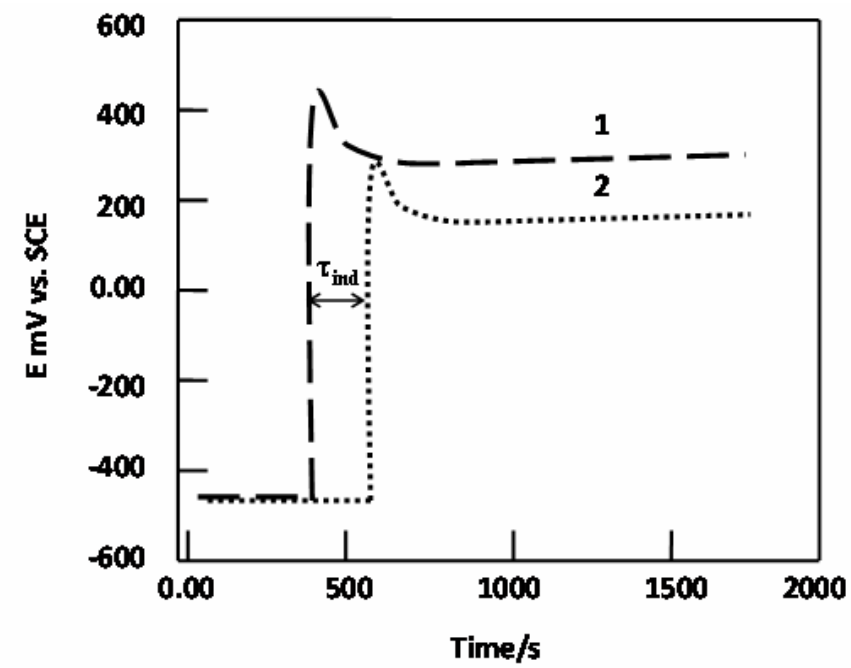

Fig. $3 E(\mathrm{mV})$ vs. $\tau(\mathrm{s})$ for electrodeposition of PAA on mild steel; [AA] $=0.5 \mathrm{M},\left[\mathrm{H}_{2} \mathrm{SO}_{4}\right]=0.05 \mathrm{M}$, $[\mathrm{OA}]=2 \times 10^{-2} \mathrm{M},[\mathrm{Ce}(\mathrm{IV})]=1 \times 10^{-4} \mathrm{M}$, current density $1 \mathrm{~mA} / \mathrm{cm}^{2}$, deposition time: (1) $1000 \mathrm{~s}$ and (2) $1500 \mathrm{~s}$.

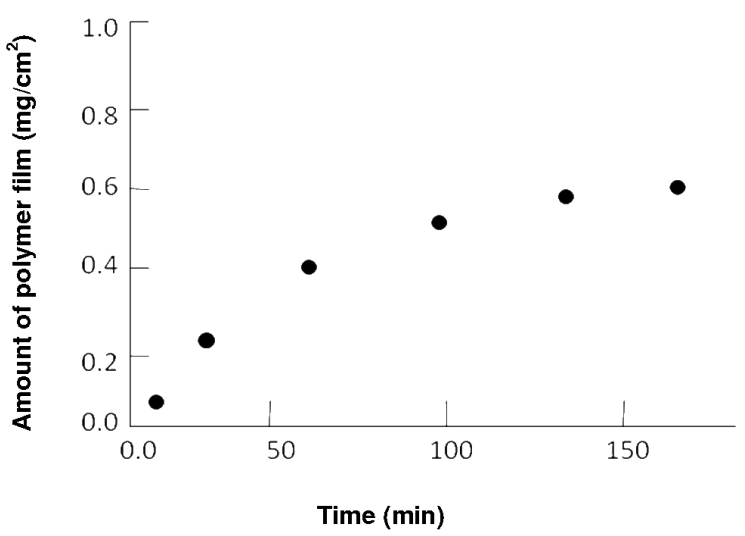

Fig. 4 Relation between the amount of polymer film and EP time at $-0.2 \mathrm{~V}$ applied voltage; $[\mathrm{AA}]=0.5 \mathrm{M}$, $\left[\mathrm{H}_{2} \mathrm{SO}_{4}\right]=0.05 \mathrm{M},[\mathrm{OA}]=2 \times 10^{-2} \mathrm{M},[\mathrm{Ce}(\mathrm{IV})]=1 \times 10^{-4} \mathrm{M}$.

Table 4 Mass difference $\Delta m$, current efficiency $\eta_{i}$ (equation 1), and film thickness $\delta$ (equation 2) for the electrodeposition of PAA on mild steel at a constant current density of $1 \mathrm{~mA} / \mathrm{cm}^{2}$; $[\mathrm{AA}]=0.5 \mathrm{M}, \quad\left[\mathrm{H}_{2} \mathrm{SO}_{4}\right]=0.05 \mathrm{M}, \quad[\mathrm{OA}]=$ $2 \times 10^{-2} \mathrm{M},[\mathrm{Ce}(\mathrm{IV})]=1 \times 10^{-4} \mathrm{M}$.

\begin{tabular}{c|c|c|c}
\hline$\tau(\mathrm{s})$ & $\Delta m(\mathrm{~g})$ & $\eta_{i}(\%)$ & $\delta(\mu \mathrm{m})$ \\
\hline 900 & -0.0007 & 22 & 0.2 \\
1200 & -0.0006 & 22 & 0.5 \\
1800 & 0.0011 & 42 & 1.6 \\
3000 & 0.0024 & 41 & 2.8 \\
\hline
\end{tabular}

A constant potential electrolysis was performed in a two-electrode cell and the formation process of the film was investigated through weight (gravimetry) and electrochemical measurements. Fig. 4 shows the amount of polymer film (or apparent coating thickness) vs. the electro polymerization time at
$-0.2 \mathrm{~V}$ of applied voltage.

Potentiodynamic polarization curves for uncoated mild steel and PAA-coated mild steel $(\sim 2.8 \mu \mathrm{m}$ thick film), recorded in an aqueous $1 \mathrm{M} \mathrm{NaCl}$ solution, are shown in Fig. 5. The Tafel extrapolations show that the PAA has caused a significant shift, $-0.31 \mathrm{~V}$ versus $\mathrm{SCE}$, of the corrosion potential $\left(E_{\text {corr }}\right)$, with respect to the value observed for uncoated mild steel $(-0.71 \mathrm{~V})$. The positive shift in $E_{\text {corr }}$ confirms that mild steel is better protected when its surface is covered by PAA. The Tafel measurements also clearly show that a substantial reduction of the corrosion current density $\left(I_{c o r r}\right)$ occurs for the PAA-coated mild steel with respect to the uncoated material. The values of $E_{c o r r}$, $I_{c o r r}$ and the corrosion rates obtained from these curves are given in Table 5. The corrosion rate of mild steel is significantly reduced as a result of the reduction of $I_{\text {corr }}$. It is important to note that the cathodic current density of PAA-coated mild steel is significantly lower than that of uncoated mild steel. This 


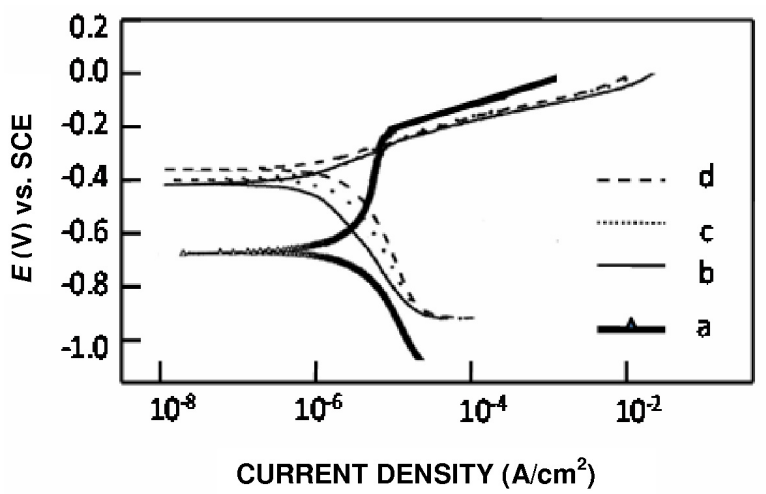

Fig. 5 Potentiodynamic polarization curves for (a) uncoated mild steel and (b, c, d) PAA ( 2.8 $\mu$ m thickness) on mild steel in an aqueous $1 \mathrm{M} \mathrm{NaCl}$ solution; sweep rate: $0.001 \mathrm{~V} / \mathrm{s}$. The PAA film was synthesized with different sweep rates: (b) 0.02 , (c) 0.05 , (d) $0.1 \mathrm{~V} / \mathrm{s}$.

Table 5 Results of potentiodynamic polarization measurements in $1 \mathrm{M} \mathrm{NaCl}$.

\begin{tabular}{l|c|c|c|c|c|c}
\hline Sample & $E_{\text {corr }}(\mathrm{V})$ & $I_{\text {corr }}\left(\mathrm{A} / \mathrm{m}^{2}\right)$ & $\beta_{a}(\mathrm{~V} / \mathrm{dec})$ & $\beta_{c}(\mathrm{~V} / \mathrm{dec})$ & $R_{p}\left(\Omega / \mathrm{m}^{2}\right)$ & $C R(\mathrm{~mm} / \mathrm{yr})$ \\
\hline Uncoated mild steel & -0.710 & 0.17 & 0.07 & 0.23 & $1.6645 \times 10^{6}$ & 0.172 \\
$\begin{array}{l}\text { PAA-coated mild steel } \\
(\sim 0.2 \mu \mathrm{m})\end{array}$ & -0.536 & 0.005 & 0.025 & 0.210 & $1.35034 \times 10^{8}$ & 0.005 \\
$\begin{array}{l}\text { PAA-coated mild steel } \\
(\sim 0.5 \mu \mathrm{m})\end{array}$ & -0.358 & 0.002 & 0.042 & 0.285 & $3.10793 \times 10^{8}$ & 0.002 \\
$\begin{array}{l}\text { PAA-coated mild steel } \\
(\sim 1.6 \mu \mathrm{m})\end{array}$ & -0.324 & 0.001 & 0.013 & 0.205 & $5.1404 \times 10^{8}$ & 0.001 \\
$\begin{array}{l}\text { PAA-coated mild steel } \\
(\sim 2.8 \mu \mathrm{m})\end{array}$ & -0.310 & 0.0005 & 0.049 & 0.359 & $1.06510 \times 10^{9}$ & 0.0005 \\
\hline
\end{tabular}

observation suggests that the PAA coating is strongly adherent and provides nearly perfect coverage of the surface. Another observation is that films formed at different sweep rates produce different shifts of the corrosion potential. Obviously, the smaller the sweep rate, the larger the positive shift of the corrosion potential. In other words, the shift of the corrosion potential is inversely proportional to the sweep rate during the film formation. The positive shift in the corrosion potential indicates an efficient protection of the metal surface by the PAA film.

The protection efficiency $(P E)$ was calculated by using the equation:

$$
P E(\%)=\frac{R_{p c}-R_{p}}{R_{p c}} \times 100
$$

where $R_{p}$ and $R_{p c}$ denote the polarization resistance of uncoated and PAA-coated mild steel, respectively. $P E$ calculated from potentiodynamic polarization data was found to be $98 \%$. These results reveal the capability of PAA to act as a protective layer against corrosion on mild steel. Furthermore, it was found that the corrosion rate depends on the thickness of the PAA layer (Table 5) and was lowest for the $\sim 2.8 \mu \mathrm{m}$ thick coating. This indicates that the thickness of the coating affects the corrosion protection of the PAA coating.

A Nyquist impedance plot [29] for uncoated mild steel is shown in Fig. 6(a). It is important to note that there was no coating on the steel surface and, therefore, passivation of the steel surface cannot be expected. Hence, the diameter of the impedance plot is equal to the value of the charge transfer resistance of mild steel. The impedance plot was modeled by the equivalent circuit depicted in Fig. 7(a). The equivalent circuit consists of the electrolyte resistance $\left(R_{S}\right)$, charge-transfer resistance $\left(R_{c t}\right)$ and double layer capacitance $\left(C_{d l}\right)$. The impedance plot of uncoated mild steel can be fitted with a semicircle, which is attributed to processes occurring on the steel surface.

The Nyquist impedance plot of PAA-coated mild steel is shown in Fig. 6(b). This impedance plot is conveniently modeled by using the equivalent circuit depicted in Fig. 7(b), which consists of the pore resistance $\left(R_{p}\right)$, coating capacitance $\left(C_{c}\right)$, chargetransfer resistance $\left(R_{c t}\right)$ and double layer capacitance $\left(C_{d l}\right)$. In both cases the constant phase element (CPE) was considered instead of the capacitance. CPE represents the deviation from the true capacitance behavior. The impedance plot of PAA-coated mild 
Table 6 Impedance parameters extracted from a fit to the equivalent circuit for impedance spectra recorded in $1 \mathrm{M} \mathrm{NaCl}$.

\begin{tabular}{c|c|c}
\hline Parameter & Uncoated mild steel & PAA-coated mild steel \\
\hline$R_{s}(\Omega)$ & 4.96 & 42 \\
$R_{p}(\Omega)$ & - & 180 \\
$C_{c}(\mathrm{~F} / \mathrm{m})$ & - & $3.4172 \times 10^{-7}$ \\
$R_{c t}(\Omega)$ & 357 & 17850 \\
$C_{d l}(\mathrm{~F} / \mathrm{m})$ & $7.9245 \times 10^{-4}$ & $8.182 \times 10^{-6}$ \\
\hline
\end{tabular}
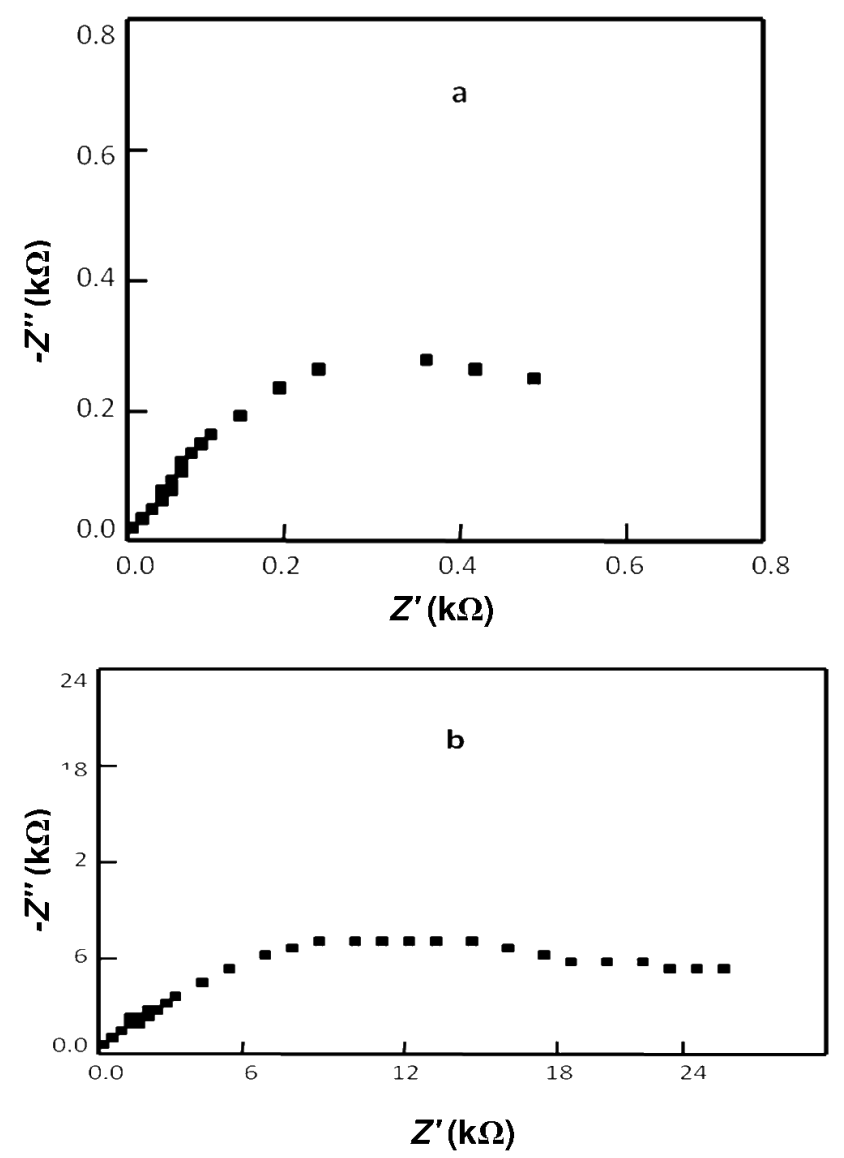

Fig. 6 Nyquist impedance plots for (a) uncoated mild steel and (b) PAA-coated mild steel. The plots were recorded at open circuit potential in an aqueous solution of $1 \mathrm{M} \mathrm{NaCl}$.

steel in Fig. 6(b) can be fitted with two semicircles, a smaller one in the high frequency range and a larger one at lower frequencies. The first semicircle is attributed to the PAA coating itself and the second one to processes occurring underneath the coating. The values of the impedance parameters obtained from fitting the experimental impedance plots for uncoated mild steel and PAA-coated mild steel to the equivalent circuits shown in Fig. 7, are given in Table 6.

The higher value of $R_{c t}$ observed for uncoated mild steel is attributed to a stable passive layer formed at the steel surface during the growth of the PAA coating and the effective barrier behavior of the PAA coating. The lower values of $C_{c}$ and $C_{d l}$ for the PAA-coated mild steel provide further support for the protection of mild steel by PAA coating. Thus, the higher values of $R_{c t}$ and $R_{p}$ and lower values of $C_{c}$ and $C_{d l}$ indicate excellent corrosion prevention for PAA coating.

$P E$ was calculated by using the following equation:

$$
P E(\%)=\frac{R_{c t p}-R_{c t}}{R_{c t p}} \times 100
$$




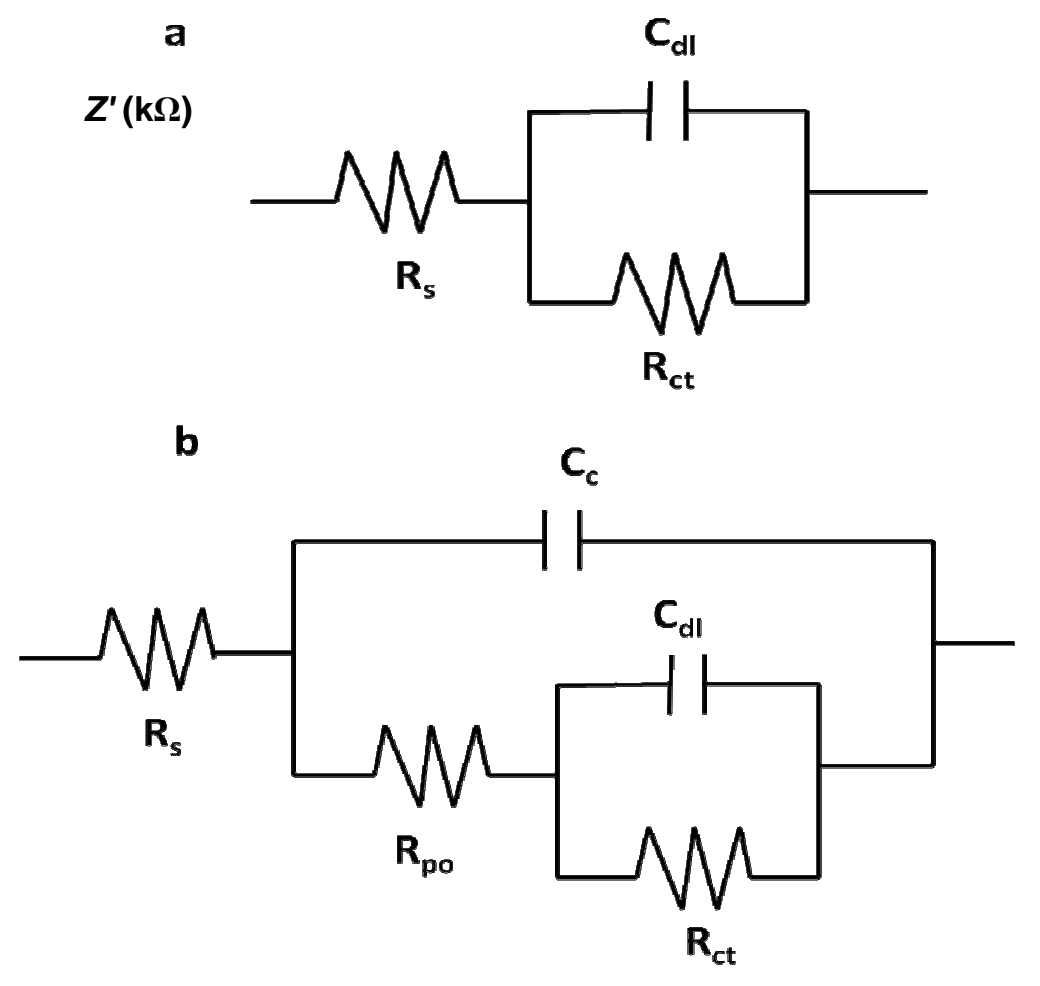

Fig. 7 Equivalent circuit models for (a) uncoated mild steel and (b) PAA-coated mild steel.

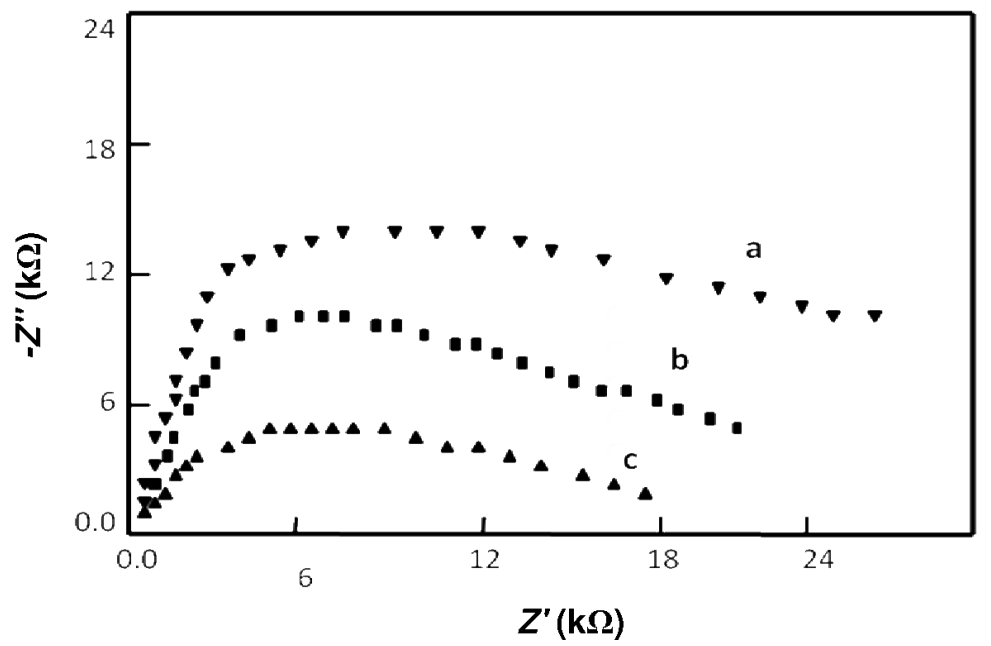

Fig. 8 Nyquist impedance plots for PAA-coated mild steel. The plots were recorded at open circuit potential in an aqueous solution of $1 \mathrm{M} \mathrm{NaCl}$ with different sweep rates: (a) 0.02 , (b) 0.05 , (c) $0.1 \mathrm{~V} / \mathrm{s}$.

where $R_{c t p}$ and $R_{c t}$ denote the charge-transfer resistance of mild steel with and without coating, respectively. $P E$ calculated from EIS data was found to be $98 \%$, which is in agreement with the results obtained for potentiodynamic polarization.

The Nyquist diagrams in Fig. 8 show that the mild steel electrode covered with different thicknesses of PAA film exhibits different values of electrochemical transfer resistance $\left(R_{c t}\right)$. As can be expected, with decreasing sweep rate used in the electrosynthetic process, the PAA film becomes thicker and more compact. $R_{c t}$ increases gradually, and the PAA film imposes a certain inhibition to the corrosion process of the steel.

\section{Conclusions}

Potentiodynamic polarization and EIS studies have revealed that PAA deposited on mild steel acts as a 
protection layer against corrosion in $1 \mathrm{M} \mathrm{NaCl}$. The study clearly shows that PAA coating provides excellent protection against corrosion and polyacrylamide can be considered as a potential coating material for protecting mild steel against corrosion in $1 \mathrm{M} \mathrm{NaCl}$ solutions.

\section{References}

[1] A.K. Chakraborty, M. Tirrell, MRS Bull. 1 (1996) 21.

[2] M.R. Porter, In: M.R. Porter (Ed.), Recent Developments in the Technology of Surfactants, Ch. 6, Elsevier Applied Science, New York, 1990.

[3] T. Grchev, M. Cvetkovska, T. Stafilov, J.W. Schultze, Electrochim. Acta 36 (1991) 1315.

[4] S. Muralidharan, K.L.N. Phani, S. Pitchumani, S. Ravichandran, S.V.K. Iyer, J. Electrochem. Soc. 142 (1995) 1478.

[5] K. Aramaki, T. Shimura, Corros. Sci. 48 (2006) 209.

[6] I. Sekine, K. Kohara, T. Sugiyama, M. Yuasa, J. Electrochem. Soc. 139 (1992) 3090.

[7] J.R. Santos, L.H. Mattoso, A.J. Motheo, Electrochim. Acta 43 (1998) 309.

[8] T. Grchev, M. Cvetkovska, 36th ISE Meeting, Ext. Abstr. 06070, Salamanca, 1985.

[9] T. Asahara, M. Seno, A.M. Tsuchiy, Kinzoku Hyoumen Gijutsu 20 (1986) 576.

[10] A.F. Bogenschutz, J.L. Jostan, W. Krusemark, Galvanotechnik 60 (1970) 127.

[11] F.S. Teng, R. Mahalingham, R.V. Subramanian, R.A.V. Raff, J. Electrochem. Soc. 124 (1977) 995.

[12] A. Desbene-Monvernary, E.S. Duboi, P.C. Lacaze, J. Electroanal. Chem. 89 (1978) 149.

[13] G. Reinhard, E. Mersiowsky, U. Rammelt, In: M. Kendig, H. Lidheiser Jr. (Eds.), Corrosion Protection by Organic Coating, PV 87-2, The
Electrochemical Society Softbound Proceedings Series, Pennington, NJ, 1987, p. 347.

[14] H. Ohno, H. Nishihara, K. Aramaki, Boshoku Gijutsu 36 (1987) 361.

[15] F. Bruno, M.C. Pham, J.E. Dubois, Electrochim. Acta 22 (1977) 451.

[16] M.C. Pham, P.C. Lacaze, J.C. Dubois, J. Electroanal. Chem. 86 (1978) 147.

[17] G. Mengoli, S. Daolio, U. Giulio, C. Folonari, J. Appl. Electrochem. 9 (1979) 483.

[18] G. Mengoli,. T. Munar, P. Bianco, M.M. Musian, J. Appl. Polym. Sci. 26 (1981) 4247.

[19] F. Beck, R. Michaelis, F. Schloten, B.R. Zinge, Electrochim. Acta 39 (1994) 229.

[20] N.G. Gaylord, N.M. Bikales, In: H.F. Mark (Ed.), Encyclopedia of Polymer Science and Technology, Vol. 1, Wiley, New York, 1987.

[21] M.N. Ster, A. Geary, J. Electrochem. Soc. 104 (1957) 56.

[22] Electrochemistry and Corrosion Overview and Techniques, Application Note CORR-4, EG and G, Princeton Applied Research, USA.

[23] M. Kendig, D. Anderson, S. Jeanjaquet, In: Surfaces, Inhibition and Passivation, PV 86-7, The Electrochemical Society Softbound Proceedings Series, Pennington, NJ, 1986, p. 149.

[24] M. Kendig, S. Jeanjaquet, In: M. Kendig, D. Scantlebury (Eds.), Advances in Corrosion Protection by Organic Coatings, PV 89-13, The Electrochemical Society Softbound Proceedings Series, Pennington, NJ, 1989, p. 186.

[25] K.C. Gupta, K. Behari, Polym. J. 19 (1987) 357.

[26] R.A. Nyquist, Infrared Spectra of Plastics and Resins, Dow Chem. Co., Midland, MI, (1961).

[27] S.J. Guerrero, P. Boldarino, J.A. Zurimendi. J. Appl. Polym. Sci. 30 (1985) 956.

[28] W. Su, J.O. Iroh, J. Appl. Polym. Sci. 65 (1997) 417.

[29] H. Shokry, M. Yuasa, I. Sekine, R.M. Issa, H.Y. El-Baradie, G.K. Gomma, Corros. Sci. 40 (1998) 2173. 